\title{
Taxonomia de Fanniidae (Diptera) do sul do Brasil - I: nova espécie e chave de identificação de Euryomma Stein
}

\author{
Lisiane Dilli Wendt ${ }^{1,2} \&$ Claudio José Barros de Carvalho ${ }^{1,3}$
}

\author{
${ }^{1}$ Departamento de Zoologia, Universidade Federal do Paraná, Caixa Postal 19020, 81531-980 Curitiba-PR, Brasil. \\ ${ }^{2}$ lisidilli@yahoo.com.br \\ ${ }^{3}$ cjbcarva@ufpr.br
}

\begin{abstract}
Taxonomy of Fanniidae (Diptera) of southern Brazil - I: a new species and a key to identification of Euryomma Stein. Euryomma Stein and Fannia Robineau-Desvoidy are the only genera of Fanniidae (Diptera) occurring in South America. The present study concerns only to Euryomma species. Identification keys to Fanniidae genera and to the species of Euryomma of southern Brazil are provided. Redescriptions of the previously recorded species and the description of Euryomma palpingens sp. nov. from Ponta Grossa, Paraná, are presented. Euryomma carioca Albuquerque is newly recorded from Santa Catarina and Rio Grande do Sul, and E. peregrinum (Meigen) from Santa Catarina. Drawings of the main diagnostic characters and male and female terminalia of all species are included.
\end{abstract}

KEYWORDS. Biodiversity, morphology, Muscoidea, Neotropical region, systematics.

\begin{abstract}
RESUMO. Taxonomia de Fanniidae (Diptera) do sul do Brasil - I: nova espécie e chave de identificação de Euryomma Stein. Euryomma Stein e Fannia Robineau-Desvoidy são os únicos gêneros de Fanniidae que ocorrem na América do Sul. A presente contribuição refere-se às espécies de Euryomma. É apresentada uma chave de identificação para os gêneros de Fanniidae e para as espécies de Euryomma que ocorrem no Sul do Brasil. Redescrições de duas espécies já conhecidas e descrição de Euryomma palpingens sp. nov. de Ponta Grossa, Paraná são apresentadas. Euryomma carioca Albuquerque é registrada pela primeira vez para Santa Catarina e Rio Grande do Sul e E. peregrinum (Meigen) pela primeira vez para Santa Catarina. São também incluídas ilustrações dos principais caracteres diagnósticos e das terminálias masculina e feminina das espécies.
\end{abstract}

PALAVRA-CHAVE. Biodiversidade, morfologia, Muscoidea, Região Neotropical, sistemática.

Os Fanniidae são uma família de Calyptrata (Diptera) encontrados em todas as regiões biogeográficas, exceto nos pólos, sendo mais predominante em regiões temperadas (Pont 1977b). Existem cerca de 285 espécies reconhecidas no mundo, distribuídas em quatro gêneros (Pont 1986a): Fannia RobineauDesvoidy, 1830; Piezura Rondani, 1866; Euryomma Stein, 1899 e Australofannia Pont, 1977. Na Região Neotropical ocorrem 79 espécies em dois gêneros: Euryomma apresentando nove espécies (Carvalho et al. 2003) e Fannia com 70 espécies (Carvalho et al. 2003; Couri 2004, 2005; Couri \& Winagraski 2005).

Fanniidae pertence à superfamília Muscoidea sendo o grupo-irmão de Muscidae (McAlpine 1989). Contudo, Pont (1977b, 1989) citou que Fanniidae é uma família basal dos Muscoidea. Ainda, Michelsen (1991) afirmou que Anthomyiidae é o grupo-irmão de Muscidae; entretanto, o autor não comentou sobre a posição de Fanniidae na superfamília.

A família Fanniidae caracteriza-se pelos adultos apresentarem a veia $\mathrm{A}_{1}+\mathrm{CuA}_{2}$ curta e a veia sub-costal não sinuosa. Ainda, apresentam na tíbia posterior na face dorsal uma forte cerda na porção sub-mediana. As larvas são achatadas dorsoventralmente e com muitas ornamentações ou simples protuberâncias; os espiráculos protorácicos possuem de três a 12 processos digitiformes (Chillcott 1961; Carvalho et al. 2003).
Os adultos de Fanniidae são encontrados em áreas de florestas sobre arbustos ou em flores (Chillcott 1961). As larvas apresentam hábito saprófago e desenvolvem-se nos mais diferentes substratos como fungos e fezes (Chillcott 1961), matéria orgânica animal ou vegetal (Malloch 1934; Holloway 1984) ou associados aos rejeitos de ninhos de abelhas (Chillcott 1958, 1961) ou ninhos de pássaros (Rozkosny et al. 1997).

Euryomma possui 10 espécies distribuídas essencialmente na região Neártica e Neotropical, com exceção da cosmopolita E. peregrinum (Meigen). A relação filogenética de Euryomma com os demais gêneros da família e a relação entre as espécies de Euryomma ainda é incerta. Chillcott (1961) citou que Euryomma é um grupo que se diversificou cedo nos Fanniidae, junto com Piezura e o grupo canicularis de Fannia. Entretanto foi feita apenas uma inferência ao grau de semelhança morfológica e não uma relação de parentesco. Contudo, Hennig (1965) refutou esta posição basal de Euryomma dentro da família.

Os adultos de Euryomma são caracterizados por apresentar o tórax com a primeira cerda dorsocentral pré-sutural menor que a metade do comprimento da segunda; duas cerdas esternopleurais fortes; asa com a veia $\mathrm{A}_{2}$ levemente curvada $\mathrm{e}$ ausência de dimorfismo sexual na cabeça (Chillcott 1961). Algumas espécies do gênero podem apresentar o hábito sinantrópico e os imaturos se desenvolvem em matéria orgânica em decomposição (Carvalho et al. 2002). 
O presente trabalho refere-se à Euryomma e é o primeiro de uma seqüência de dois trabalhos para as espécies de Fanniidae que ocorrem na Região Sul do Brasil. São apresentadas descrição de uma espécie nova, redescrições de duas espécies já conhecidas, ilustrações dos caracteres importantes para o reconhecimento das espécies, bem como chaves de identificação para os gêneros de Fanniidae e para as espécies de Euryomma.

\section{MATERIALE MÉTODOS}

O material examinado foi proveniente da Coleção Entomológica Padre Jesus Santiago Moure, Departamento de Zoologia, Universidade Federal do Paraná (DZUP), Curitiba, Paraná, Brasil; Museu Nacional da Universidade Federal do Rio de Janeiro (MNRJ), Rio de Janeiro, Brasil; e, Museu de Zoologia da Universidade de São Paulo (MZSP), São Paulo, Brasil.

Foram incluídas neste trabalho apenas espécies de ocorrência dos estados do Sul do Brasil (Rio Grande do Sul, Santa Catarina e Paraná).

A identificação das espécies de Euryomma foi feita através de chave de identificação (Carvalho \& Pamplona 1979), descrição original (Albuquerque 1956) e redescrição (Chillcott 1961), ou quando possível foram comparados com o materialtipo.

Para as espécies já conhecidas foram feitas redescrições das características mais utilizadas na identificação e dos caracteres diagnósticos, resumindo os atributos pelos quais a espécie é mais facilmente reconhecida. Ainda, foram feitos comentários sobre a taxonomia, a biologia e a distribuição geográfica de cada espécie. Para a espécie nova foi feita a descrição detalhada das principais estruturas. A terminologia empregada segue basicamente McAlpine (1981) com algumas modificações indicadas por Carvalho (1989).

Para a observação das terminálias o abdome foi retirado inteiramente e clareado com hidróxido de potássio $10 \%$ a frio, desidratado em álcool $70 \%$ e posteriormente armazenado em glicerina. Após a observação e confecção das ilustrações as terminálias foram acondicionadas em tubos plásticos contendo glicerina. Cada tubo foi afixado ao alfinete do respectivo espécime, segundo o protocolo de Gurney et al. (1964).

Ilustrações da morfologia externa e terminália foram feitas com o auxílio de microscópio estereoscópio e microscópio óptico, respectivamente, ambos com câmara clara.

No material examinado foram inseridas as siglas de instituições ou projetos que forneceram subsídios para a coleta de material o qual está depositado nas coleções citadas acima: EMPASC - Empresa de Pesquisa Agropecuária de Santa Catarina; IAPAR - Instituto Agronômico do Paraná; PROFAUPAR - Projeto de Levantamento da Fauna Entomológica do Paraná.

As listas completas de sinonímia e catalográfica das espécies foram apresentadas por Carvalho et al. (2003) e não serão repetidas neste trabalho.

\section{RESULTADOS EDISCUSSÃO}

Foram encontradas três espécies de Euryomma para a Região Sul do Brasil, incluindo Euryomma palpingens sp. nov. Euryomma carioca Albuquerque foi registrada pela primeira vez para os Estados de Santa Catarina e Rio Grande do Sul, e Euryomma peregrinum pela primeira vez para Santa Catarina. Para o Estado do Paraná foram encontradas as três espécies.

Chave de identificação para os gêneros de Fanniidae encontrados na Região Sul do Brasil

1. Asa com a veia $A_{2}$ fortemente curvada; extensão imaginária das veias anais encontra-se muito antes da margem da asa (Fig. 17). Cerda orbital inferior ausente nos machos. Primeira cerda dorsocentral pré-sutural desenvolvida, mais que a metade do comprimento da segunda. Processo baciliforme geralmente presente. Macho geralmente holóptico e fêmea dicóptica

.. Fannia Robineau-Desvoidy

1'. Asa com a veia $\mathrm{A}_{2}$ levemente curvada; extensão imaginária das veias anais encontra-se apenas próximo à margem da asa (Fig. 16). Cerda orbital inferior geralmente presente nos machos. Primeira cerda dorsocentral présutural menor que a metade do comprimento da segunda. Processo baciliforme ausente. Macho (Fig. 4) e fêmea (Figs. 1, 2 e 3) dicópticos ... Euryomma Stein

\section{Euryomma Stein}

Euryomma Stein, 1899:19. Espécie tipo: hispaniense Stein = peregrinum (Meigen, 1826: 187)

Diagnose: Euryomma é caracterizado pela ausência de dimorfismo sexual na cabeça; tórax com a primeira cerda dorsocentral pré-sutural menor que a metade do comprimento da segunda; duas cerdas esternopleurais fortes; asa com a veia $\mathrm{A}_{2}$ levemente curvada, a extensão imaginária das duas veias anais encontra-se apenas próximo à margem da asa; macho com processo baciliforme ausente e edeago alongado e bastante esclerotinizado; fêmea com duas espermatecas (Chillcott 1961).

Distribuição: Euryomma é o segundo maior gênero de Fanniidae, apresentando 10 espécies, sendo mais representativo no Novo Mundo. Na região Neártica são reconhecidas duas espécies (Chillcott 1961), e nas regiões Oriental (Pont 1977a), Afrotropical (Pont 1980), Paleártica (Pont 1986a), Austrália e Oceania (Pont 1989) apenas a espécie cosmopolita E. peregrinum. Anteriormente, na Região Neotropical (Carvalho et al. 2003) eram registradas nove espécies de Euryomma, sendo três espécies no Brasil: $E$. campineira Carvalho \& Pamplona 1979; E. carioca, E. peregrinum.

Taxonomia: a última contribuição no gênero para a Região Neotropical foi de Carvalho \& Pamplona (1979), no qual descreveram E. campineira e apresentaram a chave de identificação para todas as espécies. 
Biologia: o conhecimento sobre a biologia das espécies de Euryomma ainda é incipiente. As principais informações são acerca de E. peregrinum, espécie sinantrópica e cosmopolita cujas larvas podem se desenvolver em matéria vegetal em decomposição, como raízes e folhas ou até mesmo em plantas danificadas por outros insetos, ou vertebrados em decomposição (Rozkosny et al. 1997).

Também, Chillcott (1958) descreveu a morfologia dos imaturos de duas espécies de Euryomma do Panamá, coletadas em colônias de Eciton burchelli (Westwood) (Hymenoptera: Formicidae); os adultos foram coletados voando em torno da colônia.

Chave de identificação para as espécies de Euryomma Stein, encontradas na Região Sul do Brasil:

1. Palpo amarelo. Tórax acinzentado sem listras. Pernas amarelas, exceto tarsômeros. Tíbia anterior na face anterodorsal com uma cerda pré-apical (Fig. 11) .....

Euryomma peregrinum (Meigen)

1'. Palpo castanho. Tórax acinzentado com três listras castanhas. Pernas castanhas podendo apresentar trocânteres e tíbias amareladas a alaranjadas. Tíbia anterior na face anterodorsal sem cerda pré-apical (Figs. 10 e 12$)$

... 2

2. Macho: cerda orbital inferior presente. Fêmea: palpo de tamanho normal, sendo menor que o tamanho do flagelômero (Fig. 5). Macho e fêmea: antena com escapo e pedicelo amarelos e flagelômero castanho-escuro. Pernas com trocânteres, ápice dos fêmures e tíbias amarelados a alaranjados. Tíbia anterior na face anterodorsal com uma cerda no terço apical (Fig. 9). Abdome acinzentado, com uma faixa mediana mais escura que se prolonga lateralmente até a metade basal de cada tergito (Fig. 12)

Euryomma carioca Albuquerque

2'. Macho: cerda orbital inferior ausente. Fêmea: palpo bastante desenvolvido, sendo maior que o flagelômero (Fig. 6). Macho e fêmea: Antena com escapo, pedicelo e flagelômero castanhos. Pernas inteiramente castanhas. Tíbia anterior sem cerda na face anterodorsal (Fig. 10). Abdome acinzentado com tergito I-II amarelo translúcido (Fig. 13) ...... Euryomma palpingens sp. nov.

\section{Euryomma carioca Albuquerque, 1956}

(Figs.: 1, 5, 12, 18, 21, 24, 27, 30 e 33)

Diagnose: E. carioca é facilmente reconhecida por apresentar trocânteres e tíbias amarelo-alaranjados; tíbia anterior na face anterodorsal com uma cerda no terço apical.

Redescrição: Macho. Comprimento total: 2,8-3,2mm (n=5); asa: $2,5-3,0(\mathrm{n}=5)$.

Olhos dicópticos e nus. Cerdas frontais em número de dois pares intercalados por inúmeros cílios (Fig. 1). Cerda orbital inferior divergente; cerda orbital superior dirigida para a porção posterior da cabeça. Vita frontal, placa fronto-orbital, parafaciália, gena e face cinza-acastanhadas. Parafaciália com uma série de cílios. Escapo e pedicelo amarelados. Flagelômero castanho-escuro com forte pilosidade prateada. Arista subpubescente com a base castanho-clara e ápice castanhoescuro. Palpo castanho-escuro e clavado, com o ápice medindo cerca de 1,5 vezes a largura da base (Fig. 5). Tórax acinzentado com uma listra mediana castanha nítida que coincidem com as cerdas acrosticais e estendem-se até a base do escutelo e duas listras fracas que coincidem com as dorsocentrais (Fig. 7). Duas cerdas pré-alares. Cerda escutelar lateral ausente. Caliptras branco-amareladas. Halter branco-amarelado a amarelado. Asa hialina. Coxas castanhas. Trocânteres e tíbias amarelo-alaranjados. Fêmures castanhos com ápice castanhoclaro. Tarsos enegrecidos. Tíbia anterior na face anterodorsal com uma cerda no terço apical (Fig. 9). Coxa posterior na face posterior com um cílio. Fêmur posterior na face ventral com uma série completa de cerdas curtas e fortes, terminada em uma cerda longa. Abdome com a metade basal lateral de cada tergito acinzentada e a metade apical castanho a castanhoescura (Fig. 12). Esternito I nu. Esternito V reduzido em duas placas alongadas com três a quatro cerdas fortes e diversas cerdas mais fracas (Fig. 18). Terminália masculina (Figs. $21 \mathrm{e}$ 24): epândrio com cerdas esparsas de diferentes tamanhos, mais longo que largo, com projeção lateral nua, mais longa que o comprimento do sustilo; sustilo triangular com fortes cílios; placa cercal fortemente côncava, em forma de "U", coberta por cerdas longas e sinuosas. Edeago como nas figuras 27 e 30 .

Fêmea similar ao macho, exceto: comprimento total: 3,03,2 $\mathrm{mm}(\mathrm{n}=7)$; asa: 2,7-3,0 mm ( $\mathrm{n}=7$ ); Terminália (Fig. 33): cerco pouco mais longo que a placa anal, coberto por longas cerdas de diferentes tamanhos; placa anal mais larga que longa coberta por cerdas de diferentes tamanhos; esternito VIII reduzido em duas placas com três a quatro cerdas; esternito VII tão longo quanto largo e esternito VI mais largo que longo, ambos com séries desordenadas de cerdas. Duas espermatecas lisas e semicirculares (Fig. 33).

Comentários: É o primeiro registro da espécie para Santa Catarina e Rio Grande do Sul.

Biologia: Espécie de hábito sinantrópico (Linhares 1981; Almeida et al. 1985; Carvalho et al. 2002). Os adultos podem ser coletados em armadilhas Malaise ou iscadas com sardinhas (dados de etiqueta), ou com vísceras de galinha, rato em decomposição ou fezes humanas (Linhares 1981) e fígado de galinha (Almeida et al. 1985).

Linhares (1981) avaliando a distribuição anual de E. carioca em Campinas, São Paulo, Brasil, observou que a espécie apresenta maior abundância nos meses de agosto e outubro, contudo, ocorre durante todo o ano, mas em baixas densidades.

Material-tipo examinado: Holótipo macho (MNRJ) Brasil: 'Rio de Janeiro\Grajaú\S. Lopes 4-6-39'. Parátipos: 'Rio de Janeiro\Grajaúl S. Lopes 4-6-39' (1 macho, 1 fêmea, MNRJ). 

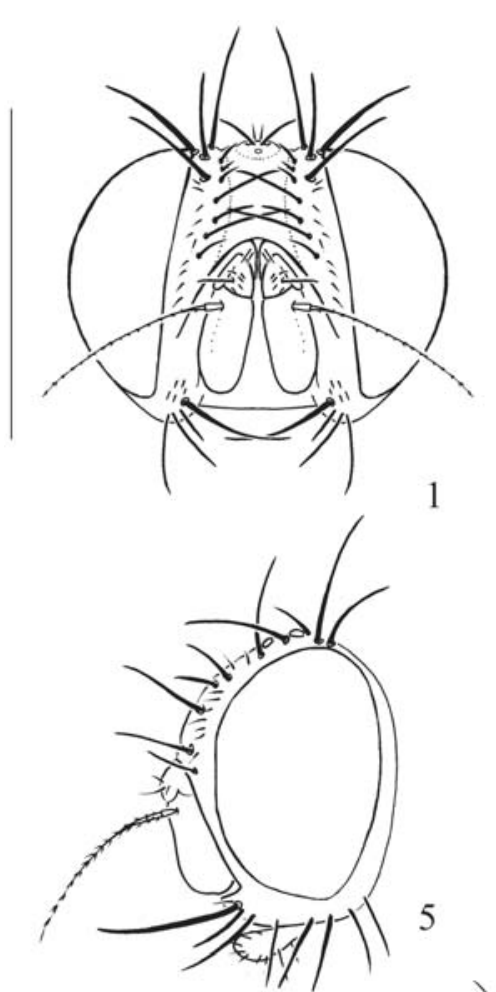

1
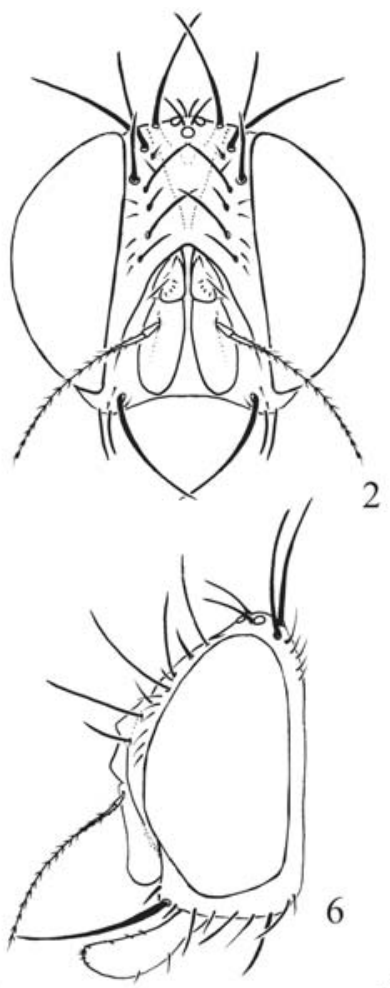

2

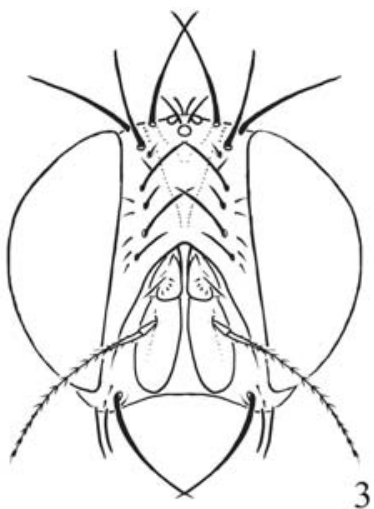

3

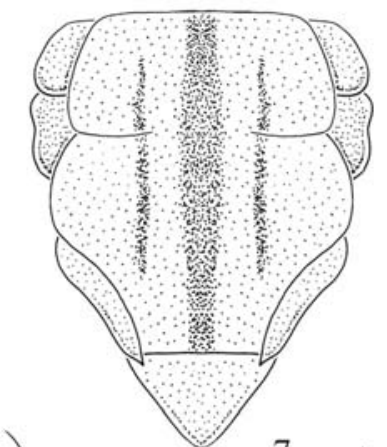

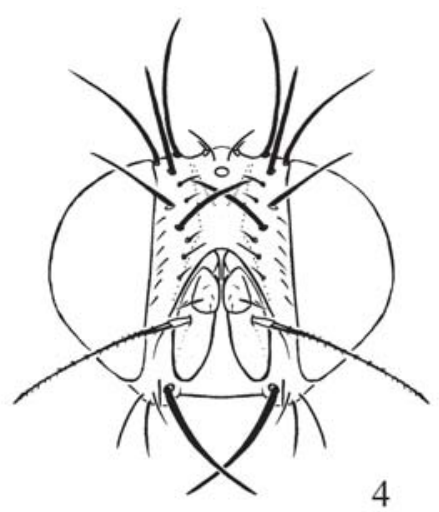

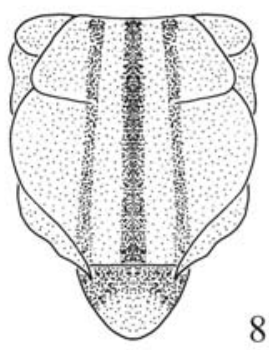

8
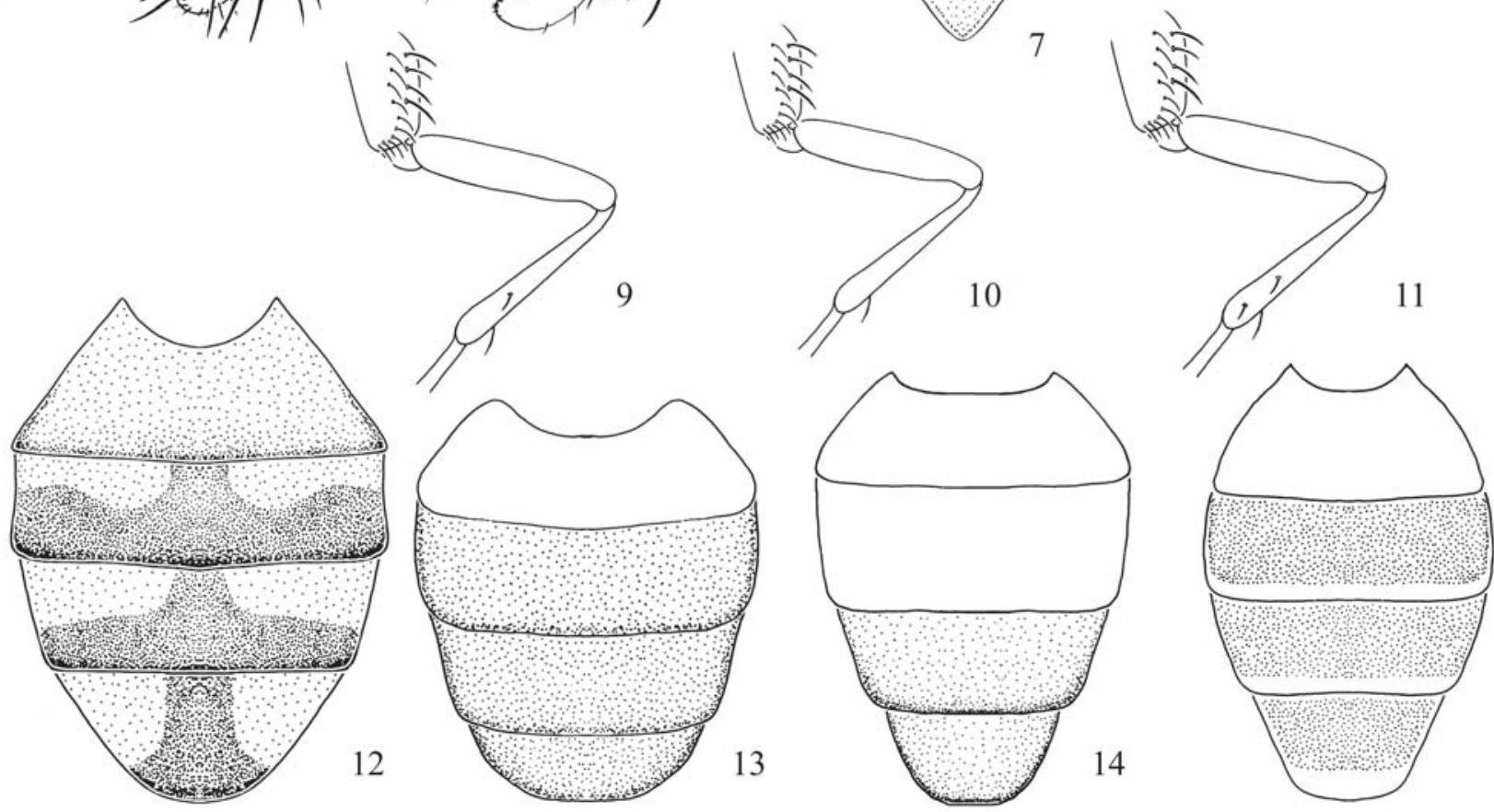

15

Figs. 1-15. Euryomma: 1-4: cabeça, vista frontal: (1) Macho, E. carioca; (2) Macho, E. palpingens sp. nov.; (3) Fêmea, E. palpingens sp. nov.; (4) Macho, E. peregrinum.; 5-6: Cabeça, vista lateral: (5) Fêmea de E. carioca; (6) Fêmea de E. palpingens sp. nov.; 7-8: Tórax: (7) E. carioca; (8) E. palpingens sp. nov.; 9-11: Perna anterior em vista anterior: (9) E. carioca; (10) E. palpingens sp. nov.; (11) E. peregrinum; 12-15: abdome: (12) E. carioca; (13) E. palpingens sp. nov.; (14) Fêmea de E. peregrinum; (15) Macho de E. peregrinum. Escala: 1 mm.

Material adicional examinado: Brasil. Paraná: Colombo, EMBRAPA, Br 476, Km 20, idem (1 fêmea, DZUP); Curitiba, 18.I.1982, L. Dudas col. (1 macho, DZUP); Curitiba, 15.VIII.1980, C. B. Jesus col. (1 fêmea, DZUP); Curitiba, Capão da Imbuia, 13.II.1985, S. J. Malkowski col. (2 fêmeas, DZUP); idem, 14.II.1985, idem (1 fêmea, DZUP); idem, 15.II.1985, idem (1 fêmea, DZUP); Guaratuba, 7.II.1965, C. Dipterologia col. (1 macho, DZUP); Jundiaí do Sul, Fazenda
Monte Verde, 12.X.1987, Levantamento Entomológico PROFAUPAR col. (1 fêmea, DZUP); idem, 19.X.1987, idem (1 fêmea, DZUP); idem, 26.X.1987, idem (4 fêmeas, DZUP); idem, 2.XI.1987, idem (2 machos, 2 fêmeas, DZPU); idem, 9.XI.1987, idem (1 fêmea, DZUP); idem, 16.XI.1987, idem (1 fêmea, DZUP); idem, 23.XI.1987, idem (1 macho, DZUP); idem, 30.XI.1987, idem (1 macho, DZUP); idem, 7.XII.1987, idem (1 macho, DZUP); idem, 14.XII.1987, idem (1 macho, DZUP); 
idem, 15.VIII.1988, idem (1 fêmea, DZUP); Ponta Grossa, 11.VIII.1986, Levantamento Entomológico PROFAUPAR col. (1 fêmea, DZUP); idem, 13.X.1986, idem (1 fêmea, DZUP); idem, 27.X.1986, idem (1 macho, DZUP); idem, 10.XI.1986, idem (1 fêmea, DZUP); idem, 24.XI.1986, idem (1 fêmea, DZUP); idem, 2.III.1987, idem (1 fêmea, DZUP); Ponta Grossa, Vilha, IAPAR, 13.IX.1999, Ganho \& Marinoni col. (1 macho, DZUP); Tijucas do Sul, Vossoroca, Br 468, Km 54, C. J. B. de Carvalho col. (1 fêmea, DZUP); Santa Catarina: Itajaí, EMPASC, XI.1988, C. G. Paloschi col. (2 fêmeas, DZUP); Nova Teutônia, IV.1971, F. Plaumann col. (1 fêmea, MZSP); idem, VIII.1971, idem (1 fêmea, DZUP); idem, V.1972, idem (1 fêmea, MZSP); idem, VI.1972; idem (1 macho, 1 fêmea, MZSP); idem, VII.1972, idem (1 macho, MZSP); Rio Grande do Sul: Pelotas, 18.X.2002, R. F. Krüger col. (1 macho, DZUP); Pelotas,

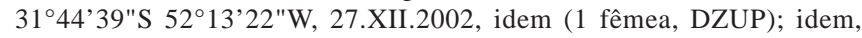
17.I.2003, idem (1 macho, DZUP); idem, 21.II.2003, idem (1 macho, DZUP)

Distribuição geográfica: Brasil: Rio de Janeiro, São Paulo, Paraná, Santa Catarina, Rio Grande Sul.

\section{Euryomma palpingens sp. nov.}

(Figs. 2, 3, 6, 8, 10, 13, 19, 22, 25, 28, 31 e 34)

Diagnose: Esta espécie destaca-se facilmente das demais por apresentar o abdome castanho com os tergitos I-II amarelo-translúcidos, pela ausência de cerda orbital inferior no macho, e pelo palpo bastante desenvolvido da fêmea.

Descrição: Holótipo macho: comprimento da cabeça ao ápice do escutelo: 1,7 mm; asa: 2,4 mm. Cabeça (Fig. 3): olhos dicópticos e nus. Espaço interocular cerca de 0,38 vezes o tamanho da cabeça ao nível do ocelo anterior. Triângulo ocelar com um par de cerdas anteriores e três pares de cílios posteriores. Cerdas frontais em número de dois pares intercalados por cílios. Cerda orbital inferior ausente. Cerda orbital superior dirigida para a face posterior da cabeça. Parafaciália com uma série de pequenos cílios. Placa frontoorbital castanho-escura. Parafaciália, gena e face castanhas com pilosidade dourada. Escapo, pedicelo e flagelômero castanho-escuros com pilosidade acinzentada. Arista castanha, com fraca pubescência. Flagelômero cerca de 2,5 vezes o comprimento do pedicelo. Palpo castanho-escuro e clavado, com o ápice medindo cerca de duas vezes a largura da base.

Tórax: Acinzentado com três listras castanho-claras que coincidem com as cerdas acrosticais e dorsocentrais, e estendem-se até a base do escutelo (Fig. 8). Cerdas acrosticais em três séries desordenadas, terminadas em um par de cerdas pré-escutelares desenvolvidas. Cerdas dorsocentrais $2+3$, a primeira pré-sutural pequena, mas distinta dos cílios de fundo. Três cerdas umerais, a interna muito reduzida e a segunda pouco menor que a externa. Uma cerda pós-umeral e uma présutural. Duas cerdas notopleurais. Duas cerdas pré-alares. Uma cerda supra-alar. Duas cerdas intra-alares e duas pós-supraalares. Escutelo castanho-claro. Um par de cerdas escutelares basais e um par de apicais desenvolvidas, um par de pré-apicais menores e cerda lateral ausente. Caliptras esbranquiçadas. Halter e asa amarelados.

Pernas: Castanhas com articulações fêmur-tibiais amareladas. Fêmur anterior na face posterodorsal com uma

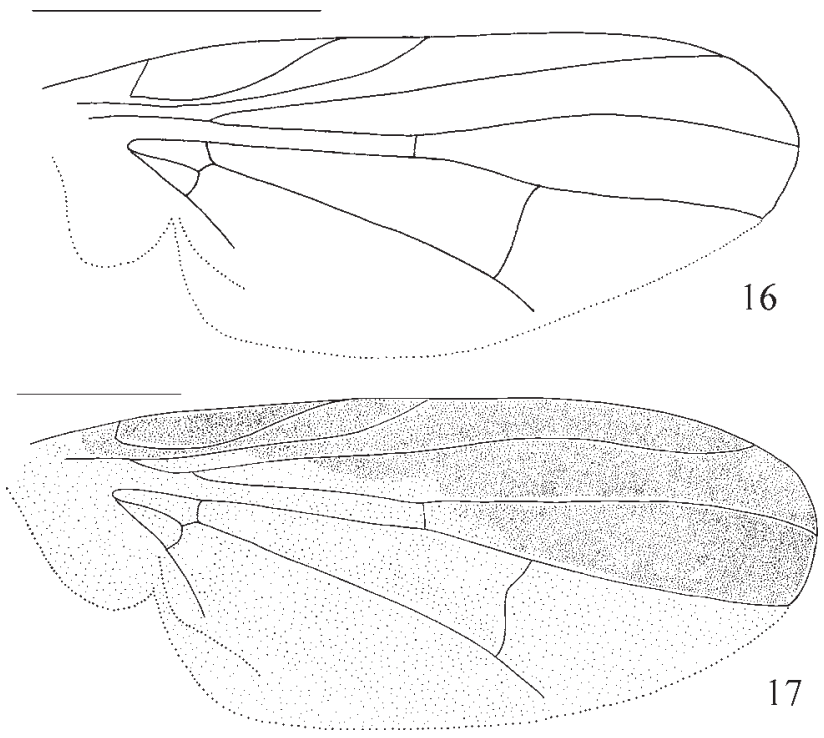

Figs. 16-17. Asa, vista dorsal: (16) Euryomma; (17) Fannia.

série completa de cerdas curtas e fortes; face posteroventral com uma série de cerdas a partir da metade apical. Tíbia anterior na face dorsal com uma cerda pré-apical (Fig. 10); face ventral e posteroventral com uma cerda apical, sendo a primeira mais forte. Basitarso anterior na face ventral com uma cerda basal. Fêmur médio na face posteroventral com uma série completa de cerdas curtas e fortes; face posterior com quatro cerdas pré-apicais, inseridas obliquamente; face anterodorsal com uma série de cerdas curtas até a metade apical e duas cerdas fortes pré-apicais. Tíbia média constrita até a metade apical e na face ventral com fraca pubescência; faces ventral e anterior com uma cerda apical forte; face anterodorsal com uma cerda pré-apical; face posterior com uma cerda mediana. Coxa posterior na face posterior com um cílio. Fêmur posterior na face anteroventral com uma série de cerdas curtas e fracas terminada em uma cerda no terço apical e uma pré-apical, ambas fortes; face anterodorsal com uma série completa de cerdas; faces dorsal e posterodorsal com uma cerda pré-apical. Tíbia posterior nas faces dorsal, anteroventral e anterodorsal com uma cerda mediana, inserida quase ao mesmo nível; faces dorsal e anterodorsal com uma cerda pré-apical, sendo a primeira mais forte; faces anterodorsal, anterior e anteroventral com uma cerda apical.

Abdome: Tergitos I-II amarelo-translúcidos (Fig. 13). Demais tergitos castanho-acinzentados. Esternito I nu. Esternito $\mathrm{V}$ formado por uma única placa (Fig. 19). Terminália (Figs. 22 e 25): epândrio quase tão longo quanto largo, coberto por cerdas de diferentes tamanhos em toda a superfície; sustilo fortemente fusionado ao epândrio, apresentando pequenos cílios em toda a sua extensão; placa cercal reduzida, densamente coberta por longas cerdas. Edeago como nas figuras 28 e 31 .

Parátipos: macho, comprimento total do corpo: 2,6 mm; asa: $2,4 \mathrm{~mm}(\mathrm{n}=1)$. Fêmea, comprimento total do corpo: 2,6$2,7 \mathrm{~mm}(\mathrm{n}=3)$; asa: $2,5-2,6 \mathrm{~mm}(\mathrm{n}=3)$. 

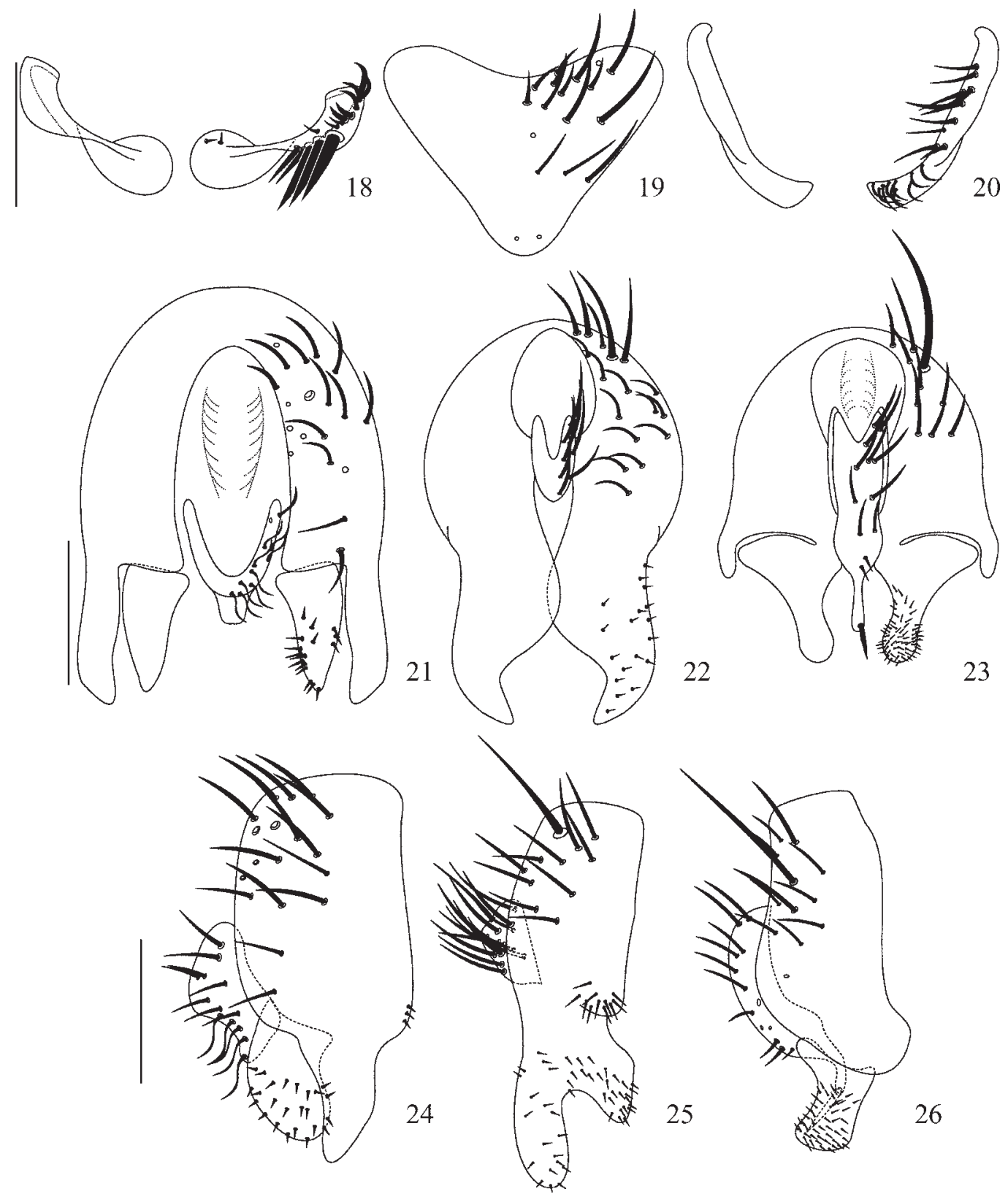

Figs. 18-26. Euryomma: 18-20: quinto esternito, vista dorsal: (18) E. carioca; (19) E. palpingens sp. nov.; (20) E. peregrinum; 21-23: Epândrio, placa cercal e sustilos, vista dorsal: (21) E. carioca; (22) E. palpingens sp. nov.; (23) E. peregrinum; 24-26: Epândrio, placa cercal e sustilos, vista lateral: (24) E. carioca; (25) E. palpingens sp. nov. (26) E. peregrinum. Escala: 0,2 mm.

Fêmea semelhante ao macho, exceto: cerda orbital inferior presente (Fig. 3), palpo bastante desenvolvido (Fig. 6), cerca de 1,5 vezes o tamanho do flagelômero e praticamente duas vezes o tamanho do palpo do macho. Tíbia média sem a constrição basal e a pubescência ventral. Terminália (Fig. 34): cerco pouco mais longo que a placa anal, apresentando cerdas longas; placa anal mais larga que longa coberta por cerdas de diferentes tamanhos; esternito VIII reduzido em duas placas circulares ciliadas; esternitos VII e VI mais largos que longos. Duas espermatecas achatadas (Fig. 34).

Comentários: O holótipo encontra-se em bom estado; colado ao lado direito em triângulo; perna média direita, parte apical da tíbia posterior e tarsômeros posteriores ausentes; abdome dissecado e armazenado em glicerina em tubo plástico.

Material-tipo: Holótipo macho (DZUP): Brasil 'Ponta Grossa (V. Velha) PR\ Reserva IAPAR br 376\ Brasil 03.X.1986\ Lev. Ent. PROFAUPAR\ MALAISE'. Parátipos: 'Antonina-PR\ Reserva Sapitanduva\ BRASIL 08.IX.1986\ Lev. Ent. PROFAUPAR\ MALAISE' (1 fêmea, DZUP); 'idem, 15.IX.1986, idem' (2 fêmeas, DZUP); ‘idem, 07.IX.1987, idem' (1 macho, DZUP); 'idem, 05.X.1987, idem' (1 fêmea, DZUP); 'Ponta Grossa (V. Velha)\ Reserva IAPAR Br 376 BRASIL 04.VIII.1986\ Lev. Ent. PROFAUPAR\ MALAISE' (1 fêmea, DZUP); 'idem, 29.XIII.1986, mesmo coletor' (1 macho, DZUP); 'idem, 12.I.1987, idem' (1 fêmea, DZUP); 'idem, 11.V.1987, idem' (2 fêmeas, DZUP); Santa Catarina, 'Brasilien\Nova Teutonial $27^{\circ} 11^{\prime}$ B $5223^{\prime} \mathrm{Ll}$ Fritz Plaumann\ VII. 1972\300-500m' (1 macho, MZSP). 

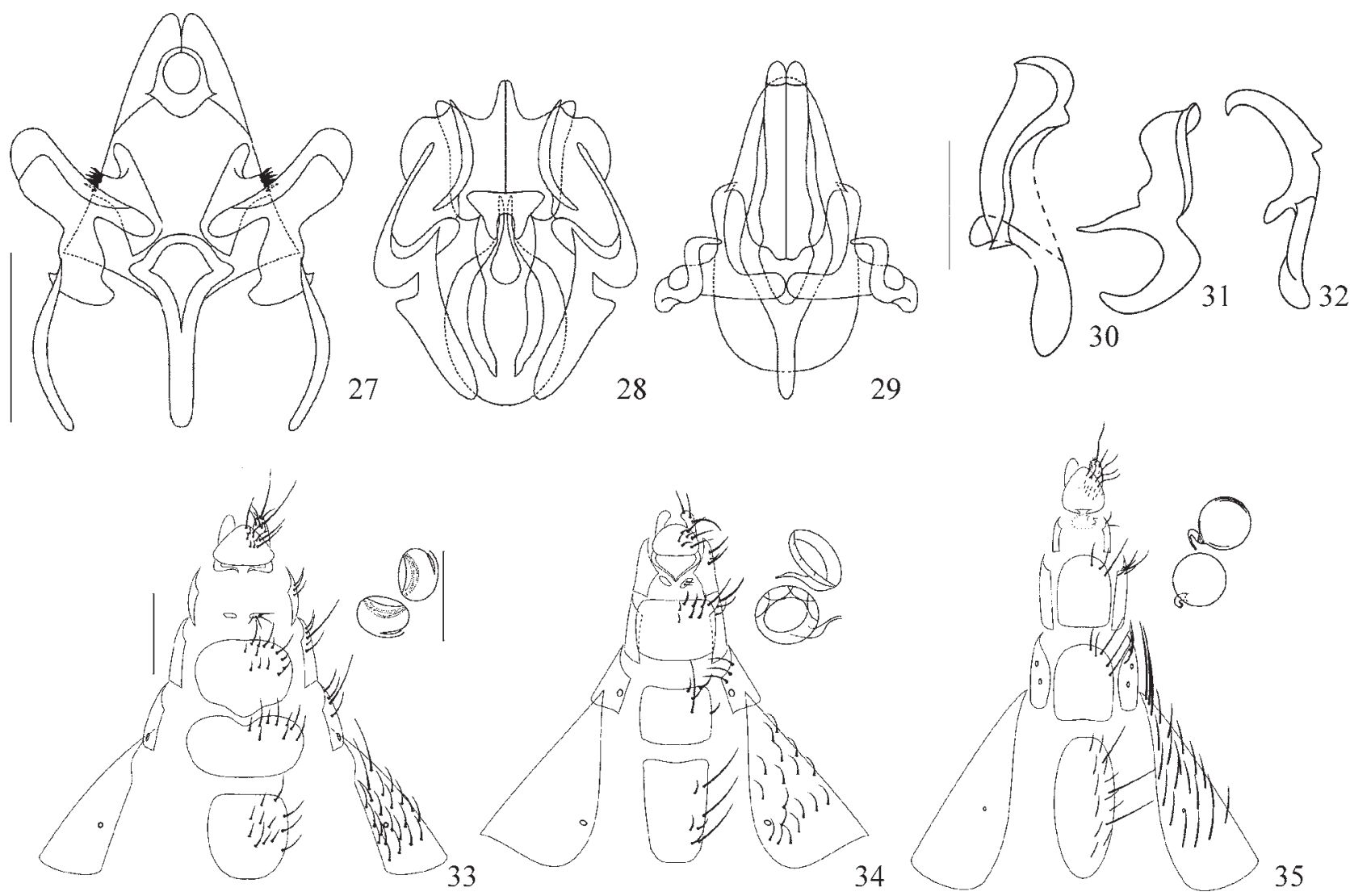

Figs. 27-35. Euryomma: 27-29: edeago e hipândrio, vista dorsal: (27) E. carioca; (28) E. palpingens sp. nov.; (29) E. peregrinum; 30-32: Edeago, vista lateral: (30) E. carioca; (31) E. palpingens sp. nov.; (32) E. peregrinum; 33-35: Terminália de fêmea, vista ventral e espermateca: (33) E. carioca; (34) E. palpingens sp. nov.; (35) E. peregrinum. Escala: 0,2 mm.

Distribuição geográfica: Brasil: Paraná, Santa Catarina.

Etimologia: O epíteto específico refere-se ao palpo das fêmeas bastante desenvolvido ( palp = palpo; ingens $=$ grande, vasto).

\section{Euryomma peregrinum (Meigen, 1826)}

(Figs.: 4, 11, 14, 15, 20, 23, 26, 29, 32 e 35)

Diagnose: E. peregrinum é facilmente reconhecida pela coloração amarela do palpo e das pernas e por apresentar na tíbia anterior na face anterodorsal uma cerda apical e uma préapical. Contudo, E. peregrinum assemelha-se com E. americanum Chillcott, 1961, espécie com distribuição nos Estados Unidos. Entretanto, estas diferem entre si principalmente pela coloração da arista negra, úmero castanhoacinzentado em $E$. peregrinum e arista amarela e úmero amarelado em E. americanum.

Redescrição: Macho: comprimento total do corpo: 3,0-3,2 $(n=4)$; asa: 2,9-3,0 $(n=4)$. Olhos dicópticos e nus. Cerdas frontais em número de três pares, a inferior menor que as demais, intercaladas por inúmeros cílios (Fig. 4). Cerda orbital inferior divergente; cerda orbital superior dirigida para a porção posterior da cabeça. Vita frontal acinzentada podendo apresentar a porção próxima à lúnula alaranjada. Placa frontoorbital com uma série de cílios. Escapo e pedicelo amarelos. Flagelômero castanho-escuro coberto por forte pilosidade prateada. Arista supubescente e castanho-escura. Palpo amarelo e clavado com o ápice medindo cerca de 1,5 vezes a largura da base. Tórax inteiramente cinza-azulado. Escutelo com ápice amarelado. Duas cerdas pré-alares. Cerda escutelar lateral ausente. Caliptras e asa amareladas. Halter amarelo. Pernas amarelas, exceto os tarsômeros pretos. Tíbia anterior na face anterodorsal com uma cerda no terço apical e uma préapical (Fig. 11). Coxa posterior na face posterior com um cílio. Tergitos I-II e ápice dos tergitos III-V amarelo-translúcidos, e o restante cinza-acastanhado (Fig. 15). Esternito V reduzido em duas placas alongadas (Fig. 20). Terminália de coloração geral amarelada (Figs. 23 e 27): epândrio mais longo que largo, com cerdas na metade basal; sustilo parcialmente fusionado ao epândrio e apicalmente coberto por pequenos cílios. Placa cercal alongada, com cerdas distribuídas em toda a superfície, afilada apicalmente e com duas fortes cerdas apicais. Edeago como nas figuras 29 e 32.

Fêmea semelhante ao macho, exceto: comprimento total do corpo: 2,9-3,5 mm (n=5); asa: 2,8-3,2 (n=5). Tergitos I-III amarelos (Fig. 14). Terminália (Fig. 35): cerco curto, coberto por cerdas longas; placa anal mais longa que larga, coberta por cílios curtos, apresentando cerdas longas e sinuosas na 
porção apical; esternito VIII reduzido em duas placas; esternitos VII e VI mais longos que largos, apresentando apicalmente uma série de cerdas de diferentes tamanhos. Duas espermatecas lisas e globosas (Fig. 35).

\section{Comentários: É o primeiro registro para Santa Catarina.}

Biologia: Espécie de hábito sinantrópico (Almeida et al. 1985; Carvalho et al. 2002). Almeida et al. (1985) coletaram adultos em ambiente urbano, no Brasil, com armadilhas iscadas com cebola em decomposição e sardinha, contudo, em baixa densidade.

Rozkosny et al. (1997) citaram que as larvas desta espécie podem se desenvolver em matéria vegetal em decomposição como raízes e folhas ou até mesmo, plantas atacadas por outros insetos, e vertebrados em decomposição.

Holloway (1984) apresentou uma descrição detalhada e uma chave de identificação para larva de terceiro ínstar da espécie.

Material-tipo: Não examinado. Holótipo fêmea, em bom estado, depositado no Naturhistorisches Museum Wien, Áustria (NMW) (Pont 1986b).

Material examinado: Brasil. Paraná: Curitiba, Santa Felicidade, 30.VII.1975, A. Imbiriba col (1 fêmea, DZUP); Curitiba, Uberaba, 23.IV.1975, idem (1 fêmea, DZUP); idem 7.V.1975, idem (1 macho, DZUP); idem, 11.VI.1975, idem (1 fêmea, DZUP); idem, 30.XI.1975, idem (1 macho, 1 fêmea, DZUP); Curitiba, 22.VIII.1980, C. B. Jesus col. (1 macho, DZUP), idem, 2.VI.1981, idem (1 macho, 1 fêmea, DZUP); idem, 15.VIII.1981, idem (1 macho, DZUP); Santa Catarina: Nova Teutônia, VIII.1971, F. Plaumann col. (1 macho, MZSP).

Distribuição geográfica: Espécie cosmopolita: Ilhas Guadalupe, Equador, Peru, Brasil, Chile, Argentina, Ilhas Juan Fernandez, Ilha da Páscoa (Carvalho et al. 2003); região Neártica (Chillcott 1961), Oriental (Pont 1977a), Afrotropical (Pont 1980), Paleártica (Pont 1986a), Austrália e Oceania (Pont 1989).

Agradecimentos. Ao Conselho Nacional de Pesquisa e Desenvolvimento Científico e Tecnológico (CNPq) pela concessão da bolsa de estudos (processo número: 133661/2004-0) para a realização do Mestrado do autor sênior e pela bolsa de produtividade em pesquisa de CJBC (processo número 302454/2005-5).

\section{REFERÊNCIAS}

Albuquerque, D. de O. 1956. Fauna do Distrito Federal. Contribuição ao conhecimento de Euryomma Stein, 1899, com descrição de uma espécie nova (Diptera, Muscidae). Boletim do Museu Nacional Rio de Janeiro 134: 1-6.

Almeida, J. R. de; C. J. B. de Carvalho \& S. R. Malkowski. 1985. Dípteros sinantrópicos de Curitiba e arredores (Paraná, Brasil). II. Fanniidae e Anthomyiidae. Anais da Sociedade Entomológica do Brasil 14: 277-288.

Carvalho, C. J. B. de. 1989. Revisão das espécies e posição sistemática de Palpibracus Rondani (Diptera: Muscidae). Revista Brasileira de Zoologia 6: 325-375.

Carvalho, C. J. B de; A. C. Pont; M. S. Couri. \& D. Pamplona. 2003. A catalogue of the Fanniidae (Diptera) of the Neotropical Region. Zootaxa 219: 1-32.
Carvalho, C. J. B. de \& D. Pamplona. 1979. Sobre uma nova espécie de Euryomma Stein, 1899 (Diptera, Fanniidae). Revista Brasileira de Biologia 39: 601-604.

Carvalho, C. J. B de; M. O. Moura \& P. B. Ribeiro. 2002. Chave para adultos de dípteros (Muscidae, Fanniidae, Anthomyiidae) associados ao ambiente humano no Brasil. Revista Brasileira de Entomologia 46: 107-114.

Chillcott, J. G. 1958. Two new species of Euryomma (Stein) (Muscidae: Diptera) from Panama. The Canadian Entomologist 90: 725731.

Chillcott, J. G. 1961. A revision of the Neartic species of Fanniinae (Diptera: Muscidae).Canadian Entomologist Supplement 14: $1-295$.

Couri, M. S. 2004. Two new species of Fannia Robineau-Desvoidy (Diptera, Fanniidae). Brazilian Journal of Biology 64: 767770.

Couri, M. S. 2005. Fannia carvalhoi sp. nov.: a new species from Peru (Diptera, Fanniidae). Revista Brasileira de Zoologia 49: 457 458.

Couri, M. S. \& E. Winagraski. 2005. New Fannia Robineau-Desvoidy from Amazonas, Brazil and new geographical record (Diptera, Fanniidae). Revista Brasileira de Zoologia 22: 645-647.

Gurny, A. B.; J. P. Kramer \& G. C. Steyskal. 1964. Some techiniques for the preparation, study and storage in microvials of insect genitalia Annual Entomological Society American 57: 240-242.

Hennig, W. 1965. Vorarbeiten zu einem philogennetischen system der Muscidae (Dipetra: Cyclorrhapha). Stuttgarter Beiträge zur Naturkunde 141: 1-100.

Holloway, B. A. 1984. Larvae of New Zealand Fanniidae (Diptera: Calyptrata). New Zealand Journal of Zoology 11: 239-258.

Linhares, A. X. 1981. Synanthropy of Muscidae, Fanniidae and Anthomyiidae (Diptera) in the city of Campinas, São Paulo, Brazil. Revista Brasileira de Entomologia 25: 231-243.

Malloch, J. R. 1934. Muscidae. In: Diptera of Patagonia and South Chile 7: 171-346.

McAlpine, J. F. 1981. Morphology and terminology: adults, p. 9-63. In: J. F. McAlpine; B. V. Peterson; G. E. Shewell; H. J. Teskey; J. R. Vockeroth \& D. M. Wood (Coords). Manual of Nearctic Diptera. Ottawa, Agriculture Canada Research Branch, Monograph 27.

McAlpine, J. F. 1989. Phylogeny and classification of Muscomorpha, p. 1397-1502. In: McAlpine \& D. M. Wood (eds.). Manual of Neartic Diptera. Ottawa, Reserch Branch Agriculture Canada, Monograph 32.

Michelsen, V. 1991. Revision of the aberrant New World genus Coenosopsia (Diptera: Anthomyiidae), with a discussion of anthomyiid relationships. Systematic Entomology 16: 85-104.

Pont, A. C. 1977a. Family Muscidae, p. 451-523. In: M. D. Delfinado \& D. E. Hardy. Catalogue of the Diptera of the Oriental Region. Vol. 3. Suborder Cyclorrhapha (excluding Division Aschiza). The University Press of Hawaii, Honolulu, 834 p.

Pont, A. C. 1977b. A revision of Australian Fanniidae (Diptera: Calyptrata). Australian Journal of Zoology. Supl. 51: 1-60.

Pont, A. C. 1980. Family Muscidae, p. 719-720. In: R. W. Crosskey (ed.), Catalogue of the Diptera of Afrotropical region. British Museum (Natural History), Londres, 1437 p.

Pont, A. C. 1986a. Family Fanniidae, p. 41-57. In: A. Sóos \& L. Papp (ed.), Catalog of the Paleartic Diptera. Hungarian Natural History Museum, Budapest, Vol. 11, $311 \mathrm{p}$.

Pont, A. C. 1986b. A revision of the Fanniidae and Muscidae described by J. W. Meigen (Insecta: Diptera). Annalen des Naturhistorischen Museums in Wien 83: 197-253.

Pont, A. C. 1989. Family Fanniidae, p. 700-701. In: N. L. Evenhuis (ed.). Catalog of the Diptera of Australasian and Oceania regions. Bishop Museum Special Publication. Bishop Museum Press, Honolulu \& E. J. Brill, Leinden. 804 p.

Rozkosny, R.; F. Gregor \& A. C. Pont. 1997. The European Fanniidae (Diptera). Acta Scientiarum Naturalium Academiae Scientiarum Bohemicae Brno 31: 1-80. 